\title{
Validation and Calibration of ASCAT Using CMOD5.n
}

\author{
Jeroen Verspeek, Ad Stoffelen, Marcos Portabella, Hans Bonekamp, Craig Anderson, and Julia Figa Saldaña
}

\begin{abstract}
The Advanced Scatterometer (ASCAT) onboard the Metop-A satellite became operational shortly after launch in 2006, and an absolute calibration using three transponders was achieved in November 2008. In this paper, we describe how the CMOD5.n ocean backscatter geophysical model function (GMF), which was derived using data from previous scatterometers onboard the European Remote Sensing 1 and 2 satellites (ERS-1 and ERS-2), was used to derive backscatter bias correction factors. The purpose is to remove the bias between ASCAT backscatter data and the CMOD5.n GMF output which allows these data to be used in place of ERS data in existing wind processing algorithms. The ASCAT Wind Data Processor, developed at the Royal Netherlands Meteorological Institute (KNMI), applies the bias correction factors to ASCAT data and uses CMOD5.n to retrieve wind vectors in order to produce an operational wind product. This resulted in a stable and high-quality ASCAT wind product since February 2007. We validate this product by comparing it to the European Centre for Medium-range Weather Forecasts (ECMWF) winds and buoy measurements. The bias correction factors indicate that ASCAT data and the GMF differ by roughly $0.3 \mathrm{~dB}$ below $55^{\circ}$ and up to $0.8 \mathrm{~dB}$ above $55^{\circ}$. A possible explanation lies in CMOD5.n which has been poorly validated in this incidence angle regime. Validation of ASCAT data using the ocean calibration method confirms this result and also indicates that bias-corrected data are everywhere within $0.3 \mathrm{~dB}$ of CMOD5.n. The wind product validation shows an rms error of $1.3 \mathrm{~m} \cdot \mathrm{s}^{-1}$ in wind speed and $16^{\circ}$ in wind direction when compared to ECMWF winds. This is better than the results achieved using ERS scatterometer data. Against buoy winds, we find an rms error wind component error of approximately $1.8 \mathrm{~m} \cdot \mathrm{s}^{-1}$. These results show that the ASCAT wind product is of high quality and satisfies its wind component accuracy requirement of $2 \mathrm{~m} \cdot \mathrm{s}^{-1}$.
\end{abstract}

Index Terms-ASCAT, backscatter, calibration, CMOD5, Metop, radar scattering, scatterometer, wind.

\section{INTRODUCTION}

$\mathbf{T}$ HE METOP-A satellite was launched on October 19, 2006 and carries the Advanced Scatterometer (ASCAT). The instrument is a real-aperture C-band vertically polarized radar with three fan beam antennas pointing to the left-hand side of the subsatellite track and three fan beam antennas pointing to the right-hand side [1].

Manuscript received January 30, 2009; revised July 3, 2009

J. Verspeek and A. Stoffelen are with the Royal Netherlands Meteorological Institute (KNMI), 3732 GK De Bilt, The Netherlands (e-mail: verspeek@ knmi.nl; stoffele@knmi.nl).

M. Portabella is with the Unidad de Tecnología Marina (UTM-CSIC), 08003 Barcelona, Spain (e-mail: portabella@cmima.csic.es).

H. Bonekamp, C. Anderson, and J. F. Saldaña are with European Organisation for the Exploitation of Meteorological Satellites, 64295 Darmstadt, Germany (e-mail: hans.bonekamp@eumetsat.int; craig.anderson@ eumetsat.int; julia.figa@eumetsat.int).

Digital Object Identifier 10.1109/TGRS.2009.2027896
During the commissioning phase, EUMETSAT performed an absolute calibration of ASCAT using three ground-based transponders. An initial external calibration campaign using a single transponder took place during November and December 2006 to give a preliminary calibration of the data. The next campaign, using all three transponders, took place between November 2007 and February 2008 and resulted in an improved calibration. However, validation activities indicated small variations in the calibration quality of the left midbeam, and these were corrected in November 2008 with further adjustments to the level-1B processor configuration. Descriptions of the three-transponder calibration procedure and results are given in [2], and the analysis of worst case errors indicates a $95 \%$ probability that the backscatter calibration precision is better than $0.15 \mathrm{~dB}$ over the transponder test site and better than $0.25 \mathrm{~dB}$ at any position around the orbit.

Two calibrated level-1B products are produced: $50-\mathrm{km}-$ resolution backscatter triplets on a $25-\mathrm{km}$ grid spacing and $25-\mathrm{km}$-resolution backscatter triplets on a $12.5-\mathrm{km}$ grid spacing. The first of these is similar in resolution to data from the European Remote Sensing (ERS) satellites and is used in this paper to compute backscatter corrections. The corrections have been interpolated for use with the $12.5-\mathrm{km}$ product and have proven to provide winds consistent with the $25-\mathrm{km}$ sampled product [3].

Ocean backscatter geophysical model functions (GMFs), in which the backscatter is a function of incidence angle, wind speed, and wind direction, have been derived using data from previous C-band vertically polarized scatterometers onboard the ERS-1 and ERS-2 satellites. If the wind vector is known, either from buoy measurements or Numerical Weather Prediction (NWP) models, then the calibrated ASCAT backscatter data can be validated by comparing them to the GMF-simulated backscatter. If there are any significant differences, then correction factors can be applied to bring data into alignment with the model, and this process effectively recalibrates ASCAT data to the same standard as the ERS scatterometers. This is useful as it allows ASCAT backscatter data to be used as a direct replacement of ERS data in existing algorithms.

The ASCAT Wind Data Processor (AWDP) has been developed at Royal Netherlands Meteorological Institute (KNMI) as part of its activities in the NWP Satellite Application Facility (NWP SAF) and is used operationally to produce the ASCAT level-2 wind product within the Ocean and Sea Ice SAF and the EUMETSAT Advanced Retransmission Service project. It applies the mentioned correction factors to the input ASCAT data before using CMOD5.n to retrieve wind vectors [4], [5]. The use of the bias correction technique has several advantages. 
First, although the initial data from ASCAT had only a preliminary calibration, bias corrections to bring them into alignment with CMOD5.n could readily be calculated, and this allowed AWDP to immediately start producing a high-quality wind product. Second, even though the ASCAT backscatter calibration has changed over the commissioning period, recalculation and verification of the bias corrections after each change have ensured that the output AWDP winds have remained constant in their quality and characteristics. ${ }^{1}$

In Section II, we validate ASCAT backscatter data by comparing them against the CMOD5.n [6] ocean backscatter GMF using a combination of visualization techniques and examination of wind-speed biases [7]. This results in a set of beam and incidence-angle-dependent bias correction factors. In Section III, we apply these to ASCAT data to bring them into alignment with the ERS GMF and make use of the ocean calibration technique [8] to confirm that this has been satisfactorily achieved. ASCAT backscatter data are operationally modified in the AWDP and, in Section IV, we validate the resulting wind vectors by comparing them against winds from the European Centre for Medium-range Weather Forecasts (ECMWF) and buoy measurements. Finally, in Section V, a summary and conclusions are presented.

\section{VALIDATION OF ASCAT DATA AND CALCULATION OF BIAS CORRECTION FACTORS}

\section{A. Midbeam and Skew Bias}

CMOD5.n gives the ocean backscatter as a function of incidence angle, wind direction (relative to the radar look direction), and neutral wind speed at 10-m height [9]. It takes the general form

$\sigma_{0}(\theta, v, \phi)=B_{0}(\theta, v)\left[1+B_{1}(\theta, v) \cos \phi+B_{2}(\theta, v) \cos (2 \phi)\right]^{1.6}$

where $\theta, \phi$, and $v$ are the incidence angle, azimuthal winddirection angle, and wind speed, respectively. $B_{0}, B_{1}$, and $B_{2}$ are functions of wind speed and incidence angle and were obtained by fitting the GMF to ERS scatterometer data which cover an incidence angle range of $18^{\circ}-55^{\circ}$. Note that ASCAT data cover incidence angles of approximately $25^{\circ}-65^{\circ}$ and that CMOD5.n has not been validated in the upper part of this range.

Each position in the left and the right ASCAT swath is illuminated by the fore, mid, and aft beams at different azimuth angles. The ASCAT level-1B data produced by EUMETSAT give these three calibrated backscatter measurements at a number of approximately equally spaced positions across each swath. For a given swath position, which we term a wind vector cell (WVC), the visualization of the ocean backscatter triplets in a 3-D measurement space is found to be a useful method for comparison with ocean backscatter GMFs [10].

Fig. 1 shows an example of such a visualization, where the three $z$-space axes $\left(z_{\text {fore }}, z_{\text {aft }}, z_{\text {mid }}\right)$ are given by $z=\sigma_{0}^{0.625}$ [9]. The backscatter triplets are shown by black points. The

\footnotetext{
${ }^{1}$ An independent change has been made to the ASCAT winds in November 2008 , where $0.2 \mathrm{~m} \cdot \mathrm{s}^{-1}$ was added to all winds in order to represent equivalent neutral winds at $10-\mathrm{m}$ height.
}

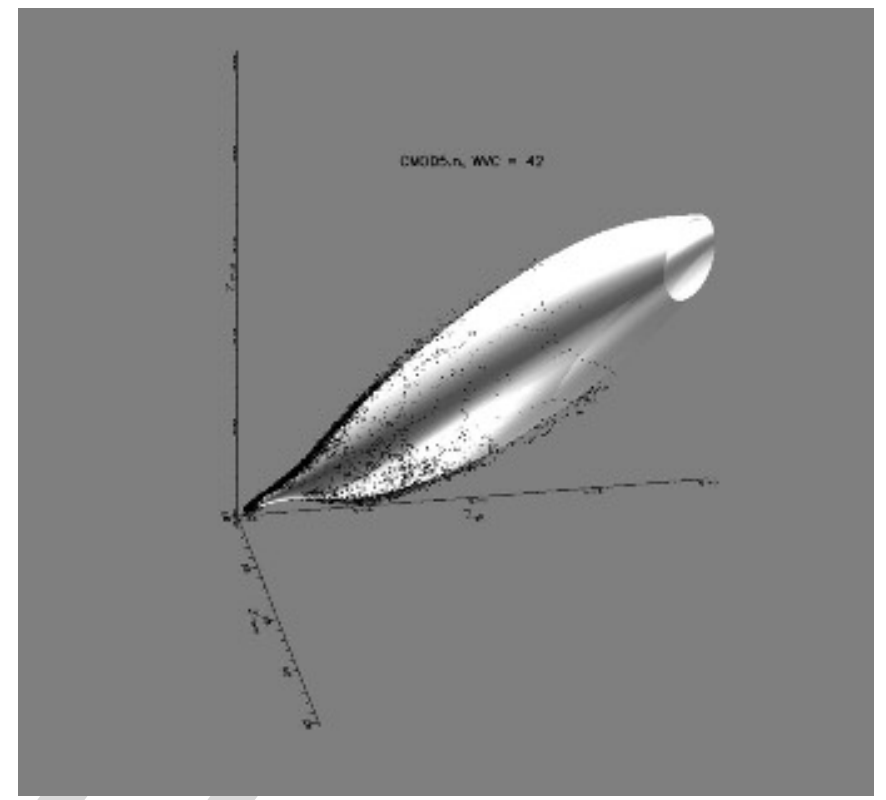

Fig. 1. Visualization of CMOD5.n and the ASCAT triplets (dots) in 3-D measurement space for WVC number 42 for wind speeds up to $30 \mathrm{~m} \cdot \mathrm{s}^{-1}$

GMF backscatter, with the incidence angle determined by the position of the WVC, reduces to a function of wind speed and direction and forms a double-folded conical surface in the 3-D measurement space. The shape of the surface is determined by the nature of the GMF and is conical because both backscatter and the magnitude of the azimuthal variation increase with wind speed. The double fold arises because wind directions $180^{\circ}$ apart give similar values for backscatter, resulting in two surfaces wrapping closely around each other. Differences between the cloud of triplets and the cone in each direction of the measurement space are, to a first approximation, caused by biases between the ASCAT data and the ERS-based GMF.

Fig. 2(a) shows a section through the wind cone at the $z_{\text {fore }}=z_{\text {aft }}$ plane and the projection of the triplets onto this plane for the outermost WVC of the right-hand swath. The data points lie above the cone, and we can manually adjust a scaling factor $s_{\text {mid }}$ for the midbeam data until the data points and the cone are judged by eye to be in good alignment. Fig. 2(b) shows the distribution of triplets after correction.

Fig. 3(a) shows the projection of the wind cone and the triplets onto the plane $z_{\text {mid }}=0$. The data points are slightly skewed with respect to the cone. We can adjust the skew by scaling the fore and aft beam data by $s_{\text {fore }}$ and $s_{\text {aft }}$ given by

$$
s_{\text {fore }}=1 / s_{\text {cone }} \quad s_{\text {aft }}=s_{\text {cone }}
$$

where $s_{\text {cone }}$ is a relative bias correction factor. We manually adjust the value for $s_{\text {cone }}$ until the skew has been removed and the data points and the cone are judged by eye to be in good alignment. Fig. 3(b) shows the distribution of triplets after correction.

This process effectively determines two of the three biases between the data and the GMF and is repeated for every WVC. This manual process is effective in finding and correcting any relatively large biases and, as the results in Sections III and IV demonstrate, produces satisfactory results. 


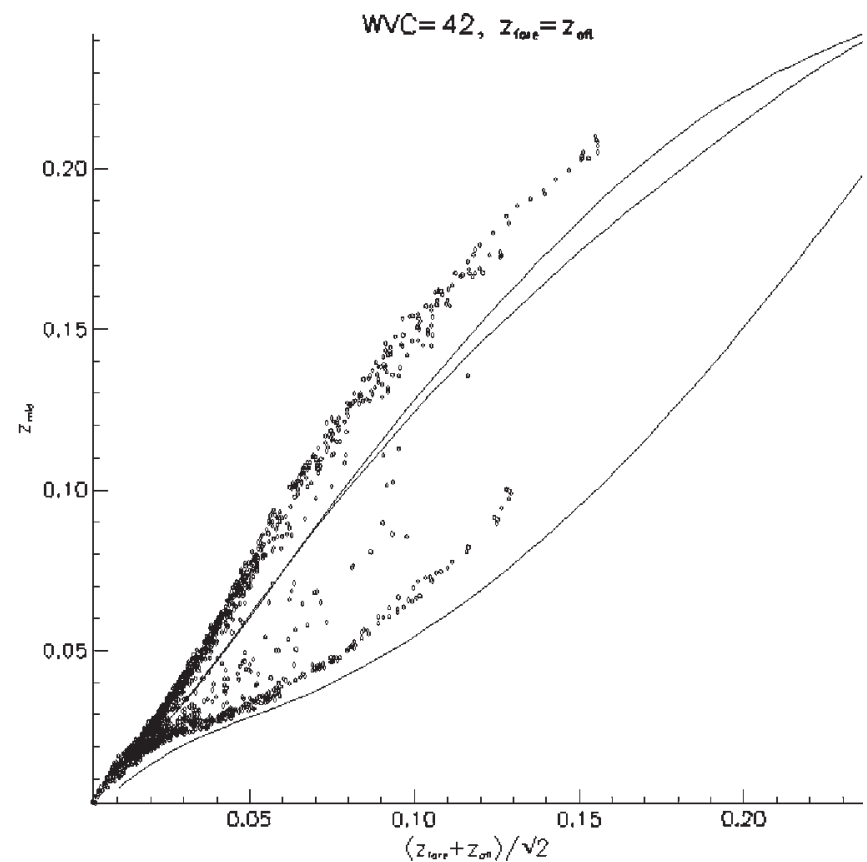

(a)

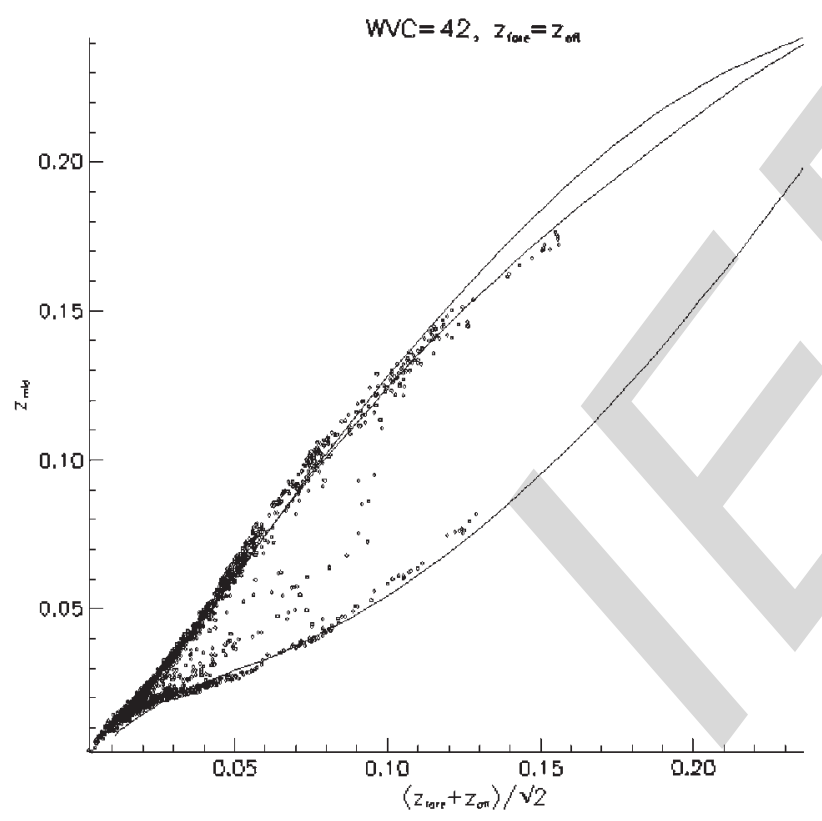

(b)

Fig. 2. Cut of the CMOD5.n cone in $z$-space at the vertical plane $z_{\text {fore }}=z_{\text {aft }}$ for WVC number 42 and projection of the ASCAT triplets (January 1, 2007) in close proximity of such plane (a) before and (b) after visual correction of the midbeam bias.

\section{B. Wind-Speed Bias}

The two bias corrections determined in the previous section bring the data into reasonable alignment with the cone. However, visual checks are not suitable for determining the final degree of freedom which is directed along the major axis of the cone. The position along this axis is mainly dependent on wind speed and hence any error results in a bias between retrieved and actual wind speeds. In this section, we determine the windspeed bias and then convert it back into scaling factors that can be applied to the ASCAT data.

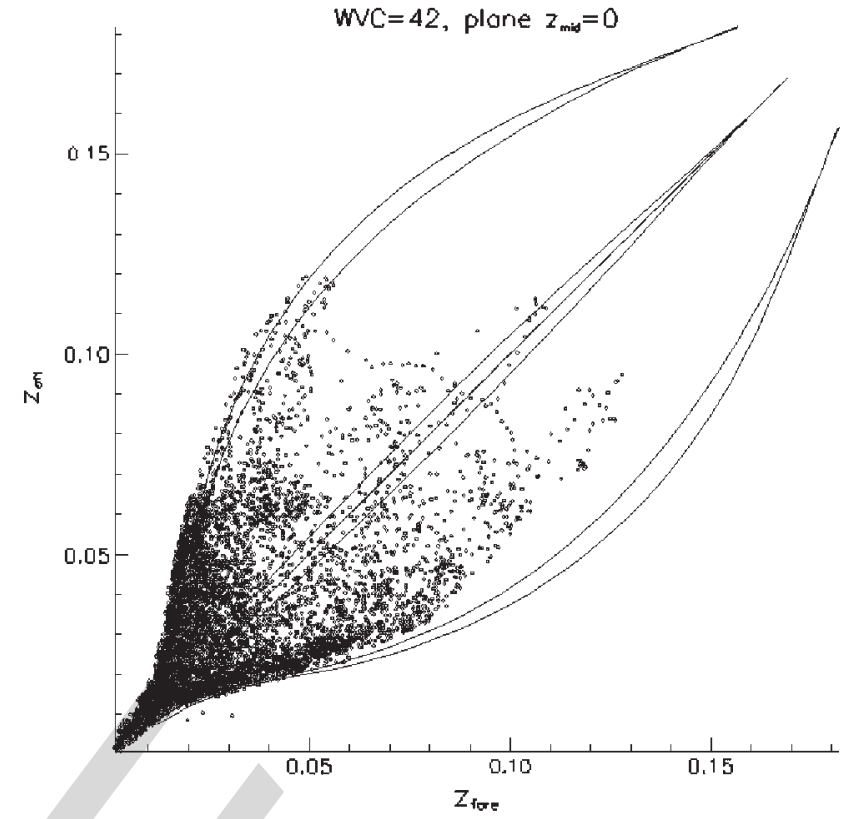

(a)

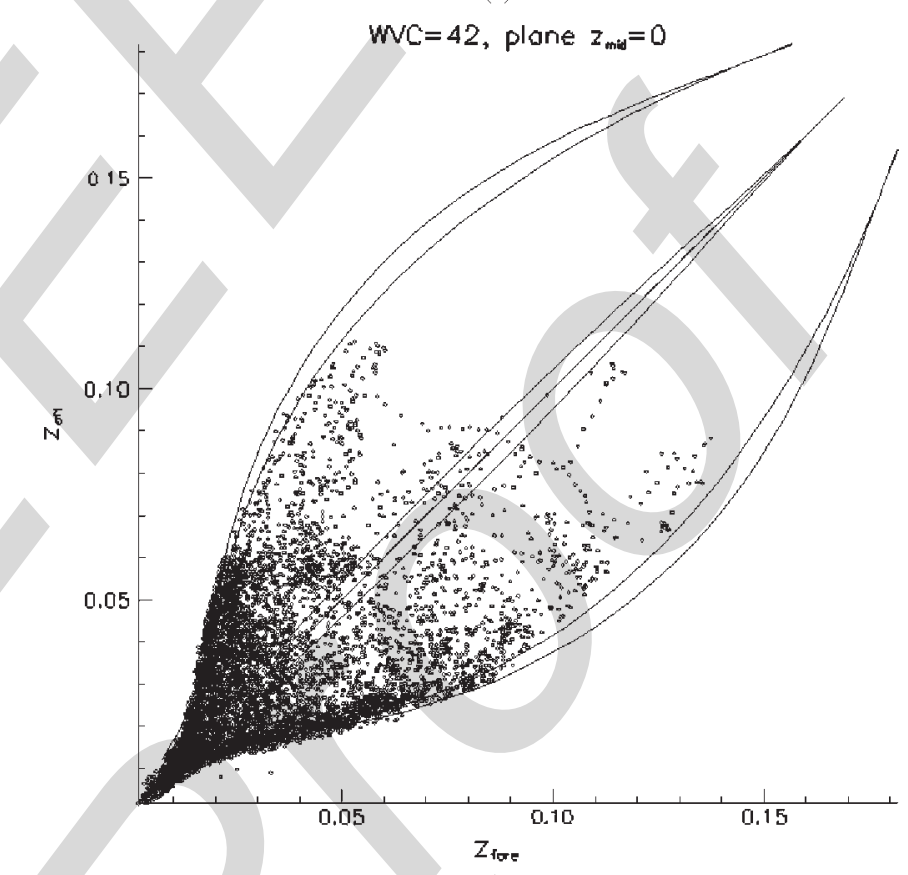

(b)

Fig. 3. Projection of the CMOD5.n cone and the ASCAT triplets (January 1,2007 ) on the plane $z_{\text {mid }}=0$ for WVC number 42 (a) before and (b) after visual correction of skew.

To determine the wind-speed bias, we remove the midbeam and skew biases in ASCAT data by applying the scaling factors determined in the previous section, retrieve winds through the inversion and ambiguity removal algorithms implemented in the AWDP, and then compare them to the ECMWF 10-m equivalent neutral winds. We note that the AWDP output and ECMWF winds are not entirely independent since the ECMWF winds are used in the ambiguity removal procedure. However, this mainly affects the direction of the retrieved winds and has only a minor effect on the retrieved wind speed.

As CMOD5.n depends quasi-linearly on neutral wind speed [11], we take the CMOD5.n wind-speed sensitivity at the mean 


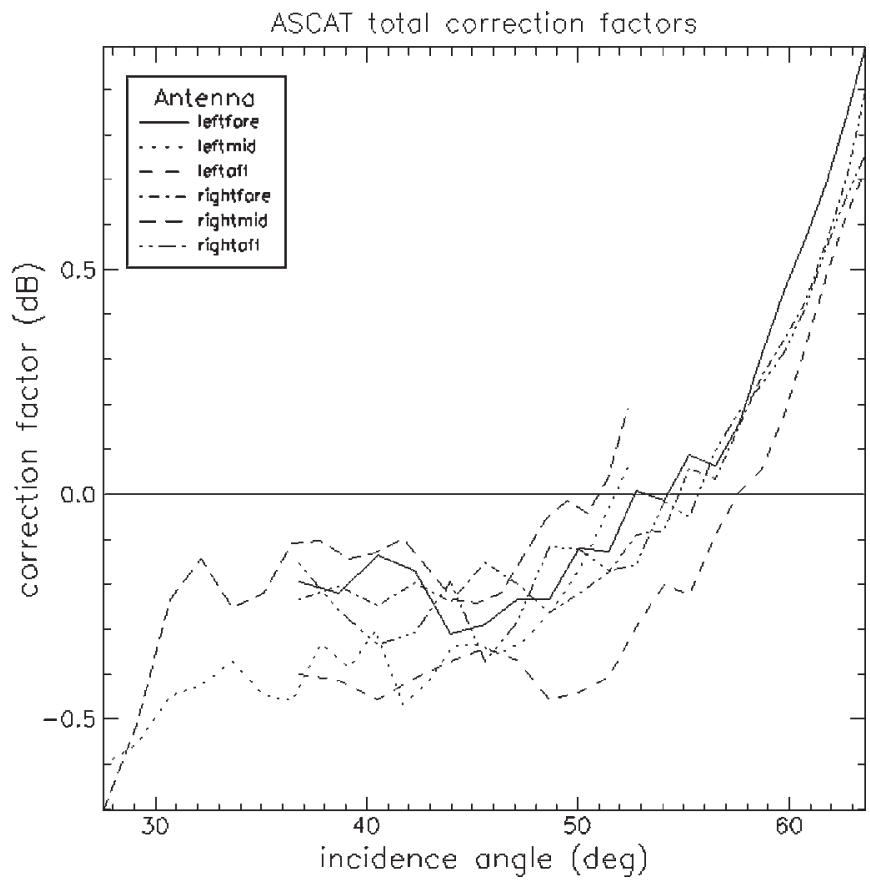

Fig. 4. Total correction factors per antenna and incidence angle.

global wind speed over the ocean, i.e., $8 \mathrm{~m} \cdot \mathrm{s}^{-1}$, to represent the full wind domain sensitivity. The correction factors to the backscatter measurements in $z$-space are then given by

$$
s_{\text {wind }}=\Delta v \frac{1}{z} \frac{d z}{d v}
$$

where $s_{\text {wind }}$ is the backscatter scaling correction factor, $\Delta v$ is the wind-speed bias, and $z$ and $d z / d v$ are the mean backscatter and CMOD5.n sensitivity at $8 \mathrm{~m} \cdot \mathrm{s}^{-1}$. Hence, the final scaling factors, which remove the midbeam, skew, and wind-speed biases, are given by

$$
\begin{aligned}
S_{\text {FORE }} & =s_{\text {wind }} / s_{\text {cone }} \\
S_{\text {AFT }} & =s_{\text {wind }} s_{\text {cone }} \\
S_{\text {MID }} & =s_{\text {wind }} s_{\text {mid }} .
\end{aligned}
$$

Fig. 4 shows the final correction factors as a function of incidence angle for each beam. Below approximately $55^{\circ}$, these indicate that the calibrated ASCAT data are about $0.3 \mathrm{~dB}$ less than the CMOD5.n GMF in all beams. This is larger than the expected ASCAT calibration accuracy and indicates that there is a difference between the calibrated data from ASCAT and the calibrated ERS data used to derive CMOD5.n. Above 55 we see that the calibrated ASCAT data become larger than the GMF by up to $0.8 \mathrm{~dB}$ at extreme far range. This could point to deficiencies in CMOD5.n which has never been validated at such large incidence angles.

Note that the correction factors in Fig. 4 are similar for all beams, indicating that the interbeam biases are small and that it may therefore be possible to use only a single set of incidenceangle-dependent correction factors for all beams. Such a set of correction factors could be incorporated into CMOD5. $n$ to give an ocean backscatter GMF that is consistent with the ASCAT three-transponder calibration.

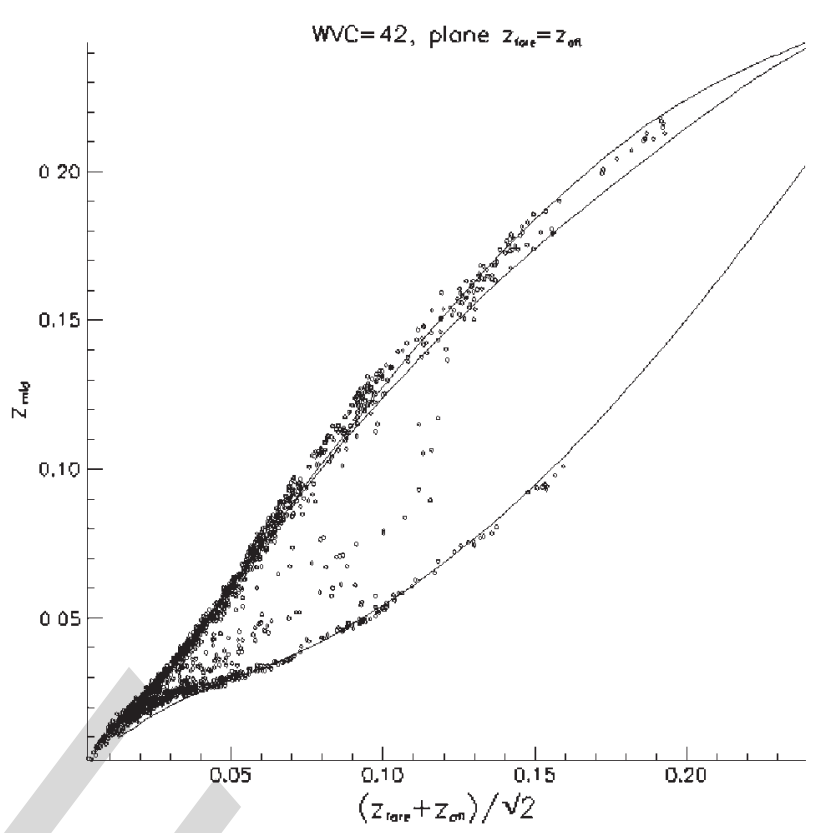

(a)

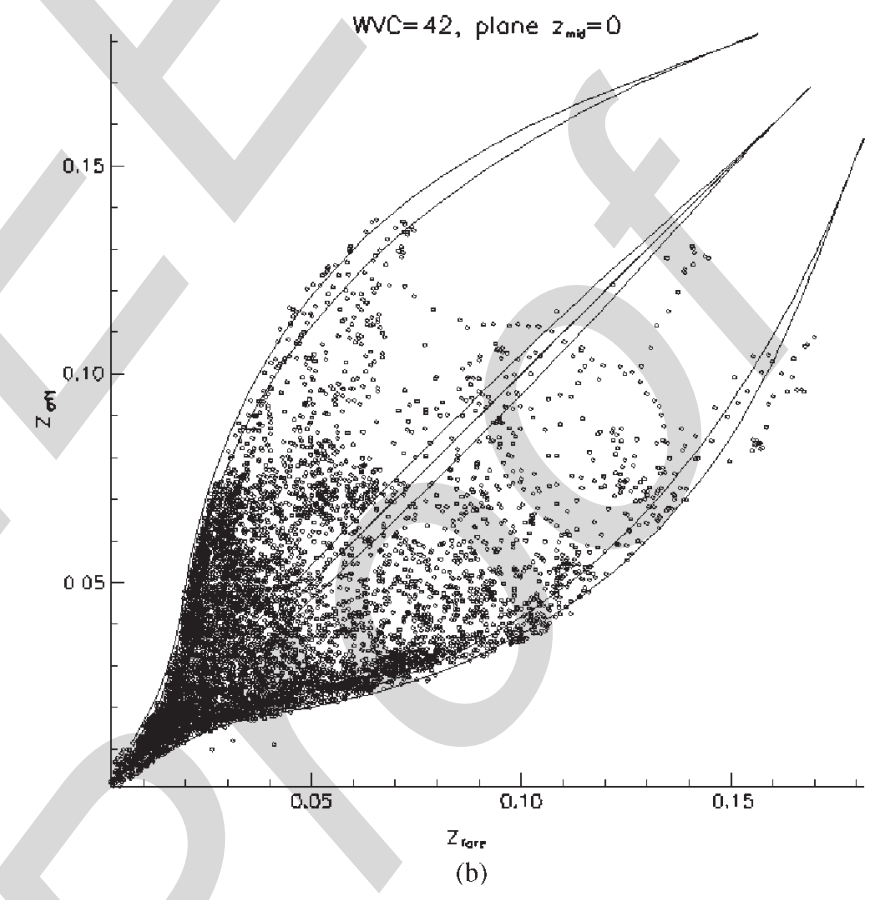

Fig. 5. Same as Figs. 2(b) and 3(b), respectively, but with all bias corrections applied to the triplets.

\section{VALIDATION OF BIAS CORRECTION}

The bias correction coefficients derived in the preceding section are used within AWDP to modify the ASCAT backscatter data before retrieving ocean winds using CMOD5.n. In order to achieve high-quality winds, it is essential that the correction coefficients are effective in bringing the data into alignment with the GMF.

We can test this qualitatively by visually comparing the modified data and GMF.

1) Fig. 5(a) and (b) shows the same as in Figs. 2(b) and 3 (b), respectively, but this time with all biases removed. Compared to the earlier figures, we see that the triplets are 


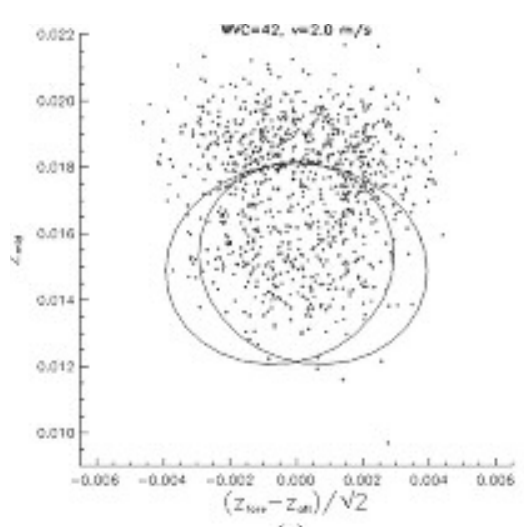

(a)

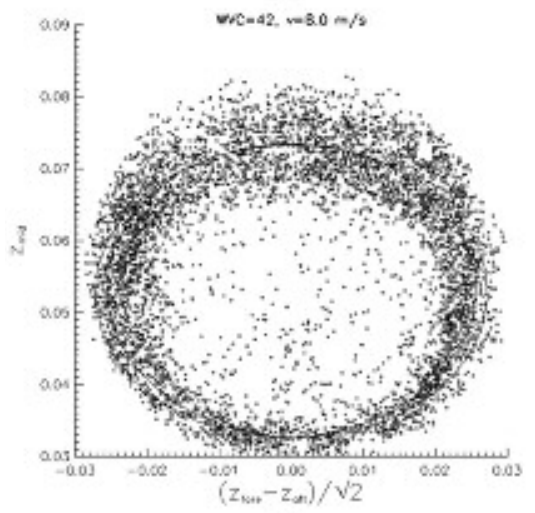

(c)

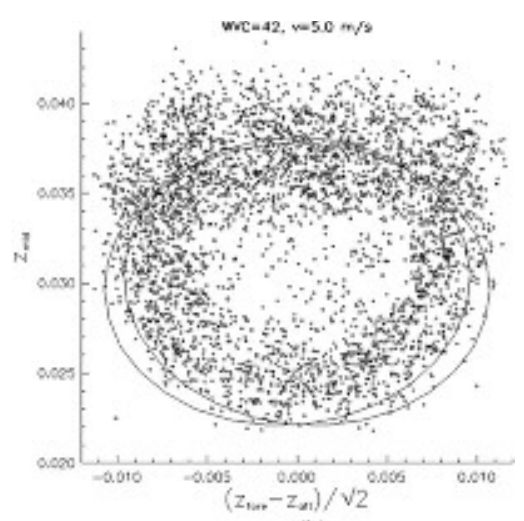

(b)

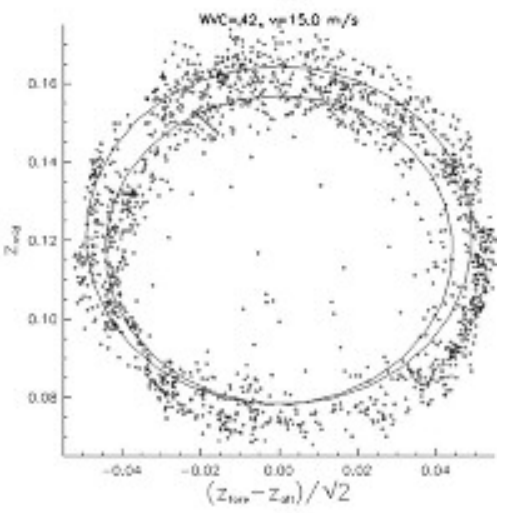

(d)

Fig. 6. Visualization for WVC 42 of (dots) the corrected triplets and (ellipses) CMOD5.n for several intersections of the cone with the plane $z_{\mathrm{fore}}+z_{\mathrm{aft}}=2 z_{\mathrm{ref}}$. ASCAT data from March 5-11, 2007 are used. The intersections correspond to the following equivalent neutral wind speeds: (a) $2 \mathrm{~m} \cdot \mathrm{s}^{-1}$, (b) $5 \mathrm{~m} \cdot \mathrm{s}^{-1}$, (c) $8 \mathrm{~m} \cdot \mathrm{s}^{-1}$, and (d) $15 \mathrm{~m} \cdot \mathrm{s}^{-1}$.

now stretched away from the origin toward higher speed values but remain consistent with the GMF cone.

2) Fig. 6 shows the intersection of the cone with the plane $z_{\text {fore }}+z_{\text {aft }}=2 z_{\text {ref }}$ and nearby triplets for the outermost WVC of the right-hand swath. A specific value of $z_{\text {ref }}$ corresponds to an approximately constant wind-speed value. In this figure, the match between modified data and GMF is generally good, although, for low wind speeds, there is a small displacement. Plots for other WVCs show similar results.

However, as a quantitative test, we use the ocean calibration technique [8] to assess the difference between corrected data and the GMF. This method is based on the analysis of a large measurement data set to estimate Fourier coefficients that can be directly compared to those in the CMOD5.n GMF. For any particular WVC in any beam, the incidence angle is very nearly constant around the orbit and we can model the backscatter with

$$
\sigma_{0}(v, \phi)=B_{0}(v)\left[1+B_{1}(v) \cos \phi+B_{2}(v) \cos (2 \phi)\right]^{1.6}
$$

which is of the same form as CMOD5.n. The mean backscatter is essentially determined by the value of $B_{0}$ with small contributions from $B_{1}$ and $B_{2}$. In $z$-space, where $z=\sigma_{0}^{0.625}$, this becomes

$$
z(v, \phi)=\frac{1}{2} a_{0}(v)+a_{1}(v) \cos \phi+a_{2}(v) \cos (2 \phi)
$$

where $a_{0}=2 B_{0}^{0.625}, a_{1}=B_{1} B_{0}^{0.625}$ and $a_{2}=B_{2} B_{0}^{0.625}$.
Integrating over the azimuth angle gives

$$
a_{n}(v)=\frac{1}{\pi} \int_{0}^{2 \pi} z(v, \phi) \cos (n \phi) d \phi, \quad n=0,1,2 .
$$

To evaluate this, we split the data into wind-speed and azimuthangle bins. Bins are defined so that they are large enough to contain a certain minimum number of measurements and small enough to provide a good approximation of the integral. In the following, indices $i$ and $j$ refer to wind-speed bin $i$ and azimuth-angle bin $j$, respectively. Index $k$ is used to refer to an individual measurement $z_{k}$. Parameters $I, J$, and $K$ refer to the total number of bins or measurements, so $i=1,2, \ldots, I$, $j=1,2, \ldots, J$, and $k=1,2, \ldots, K(i, j)$.

The mean $z$ in a fixed wind-speed row is

$$
z(i)=\frac{1}{J} \sum_{j=1}^{J} \frac{1}{K(i, j)} \sum_{k=1}^{K(i, j)} z_{k}(i, j)
$$

Summation over the wind-speed rows gives

$$
z=\frac{1}{K J I} \sum_{i=1}^{I} K J(i) z(i)
$$

with

$$
K J(i)=\sum_{j=1}^{J} K(i, j) \quad K J I=\sum_{i=1}^{I} \sum_{j=1}^{J} K(i, j) .
$$




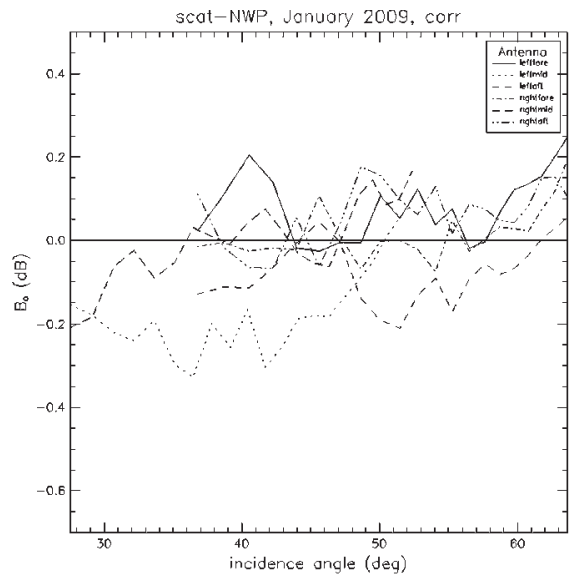

(a)

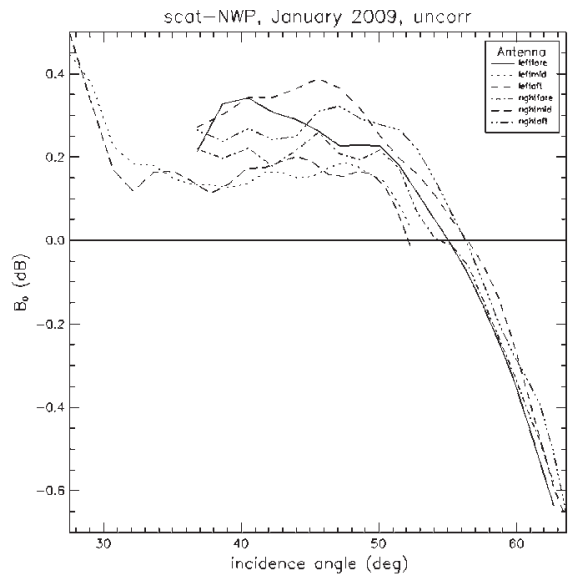

(b)

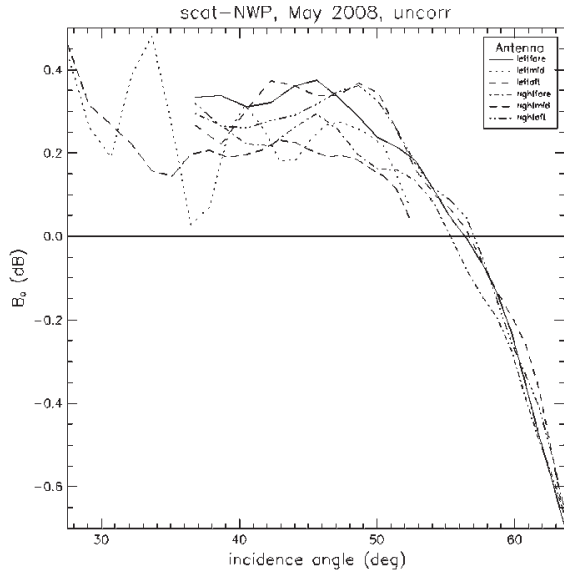

(c)

Fig. 7. Average difference between the ASCAT measurements and the ECMWF simulated measurements (using CMOD5.n GMF) as a function of incidence angle for the six ASCAT antenna beams. (a) With bias corrections, data from January 2009. (b) Without bias corrections, data from January 2009. (c) Without bias corrections, data from May 2008.

The relation with $a_{0}$ and $B_{0}$ is now simply given by $z=a_{0} / 2=B_{0}^{0.625}$. Note that we use a weighted average with weights $\sim 1 / K(i, j)$. As the data set is not uniformly distributed over azimuth angle, the weight function ensures that each azimuthal bin contributes equally to the summation. A similar derivation can be made for $B_{1}$ and $B_{2}$. More details of this procedure can be found in [10] and [12].

This method needs only a few days of collocated ASCAT data and ECMWF winds to produce a good estimate of difference in $a_{0}$. We then use CMOD5.n with the ECMWF winds to calculate model backscatter values corresponding to the measured values and again apply the process as described earlier. The difference between the two values of $a_{0}$ then gives an estimate of the mean difference between model and measurement backscatter.

Fig. 7(a) shows the difference between the corrected data and the model as a function of incidence angle. We see that the difference is less than $0.2 \mathrm{~dB}$ (apart from the left midbeam which is less than $0.3 \mathrm{~dB}$ ) and shows no systematic trend. The magnitude of this difference is similar to that shown by bias-corrected ERS data [8], [13] and similar to the expected accuracy in the ASCAT data. This indicates that the bias correction procedure is effective. We also note that sensitivity studies using CMOD5.n show that an error in backscatter of $0.2 \mathrm{~dB}$ corresponds to an error of approximately $0.2 \mathrm{~m} \cdot \mathrm{s}^{-1}$ in wind speed.

As a comparison, Fig. 7(b) shows the difference between the original unmodified ASCAT data and the model. Below $55^{\circ}$ incidence, we find a difference of around $0.3 \mathrm{~dB}$ in all beams, which, as discussed before, indicates a small difference between the ASCAT and ERS calibrations. Above $55^{\circ}$, the difference rises to about $0.6 \mathrm{~dB}$, which could possibly be due to inaccuracies in the GMF.

Since the beginning of ASCAT operations, the calibration of level-1B data has been adjusted several times as additional transponder data were collected and calibration algorithms were refined. Fig. 7(c) is similar to Fig. 7(b) but examines an older set of ASCAT data with a slightly different calibration. Note that there is an oscillation in the low incidence part of the left midbeam. However, applying the corrections to the older data set from Fig. 7(c) will produce a picture almost identical to Fig. 7(a) (not shown). The bias calculation and removal procedures are effective in removing the oscillation. This demonstrates that when the bias correction factors are recalculated every time the ASCAT calibration is modified, then the bias-corrected data do not show any changes in their characteristics.

These results indicate that the correction factors determined in the previous section are effective in bringing ASCAT data into agreement with CMOD5.n. Hence, we can expect that the modified ASCAT data will produce good results from AWDP which uses the CMOD5.n GMF to retrieve wind vectors. More generally, the corrections applied to the ASCAT data bring them to the same calibration standard as data from the ERS scatterometers and allow them to be used in any existing ERS processing algorithm.

\section{VALIDATION OF RETRIEVED WINDS}

ASCAT data are modified using the bias correction factors derived in Section II and used operationally in the AWDP to produce the ASCAT level-2 wind product. To confirm that the process is functioning as expected, we compare the retrieved winds against ECMWF winds and buoy measurements.

The dashed line in Fig. 8(a) shows the bias between the winds produced by the AWDP and ECMWF. This is everywhere below $0.1 \mathrm{~m} \cdot \mathrm{s}^{-1}$ with no obvious trends. As a comparison, the dotted line in Fig. 8(a) shows the bias when the original uncorrected ASCAT data are used. Here, we find the AWDP winds overestimated in the near range by about $0.4 \mathrm{~m} \cdot \mathrm{s}^{-1}$ and underestimated at far range by the same amount. Poorer results from unmodified data are to be expected since we know from the previous sections that there are systematic differences between the calibrated data and the CMOD5.n GMF used in the AWDP retrieval algorithms.

The wind-direction bias is small, on the order of $1^{\circ}$ (not shown). The wind-direction standard deviation (SD) is shown in Fig. 8(b). Fig. 8(c) shows the SD for the $u$ and $v$ wind components (scatterometer-NWP). Overall, the SD is somewhat lower 


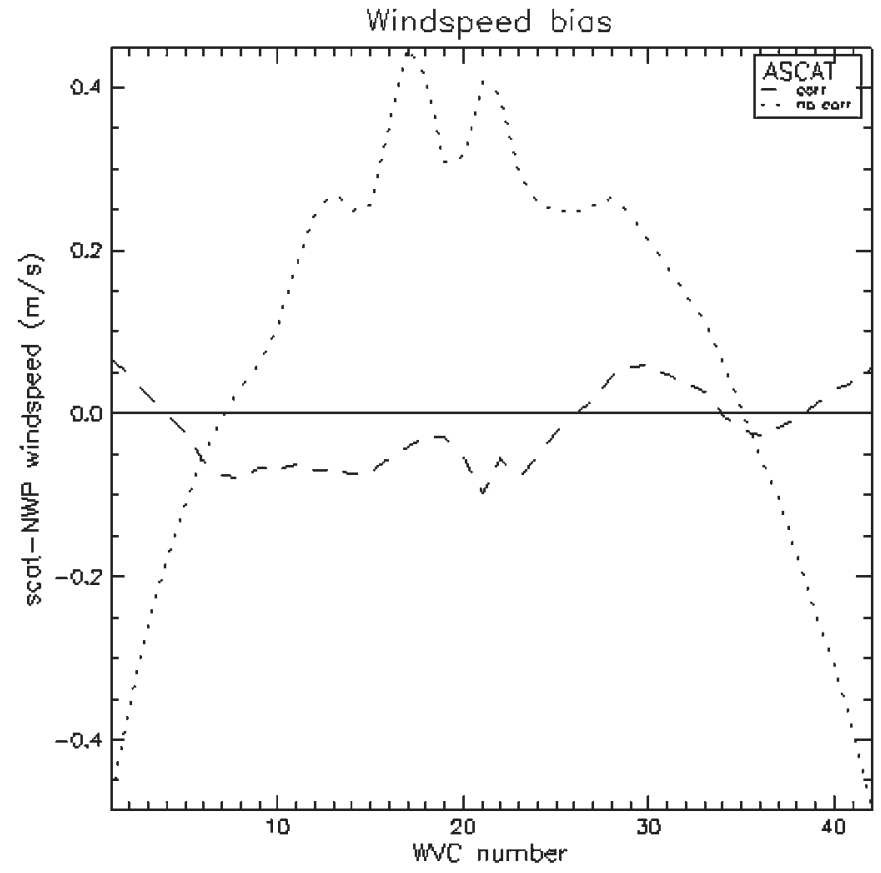

(a)

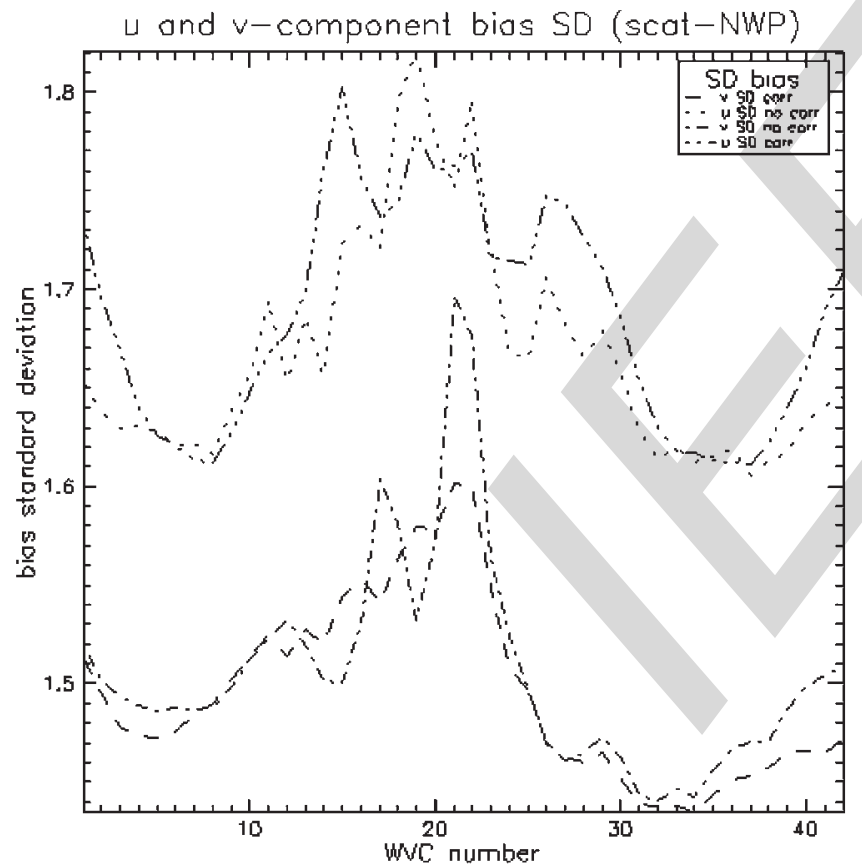

(c)

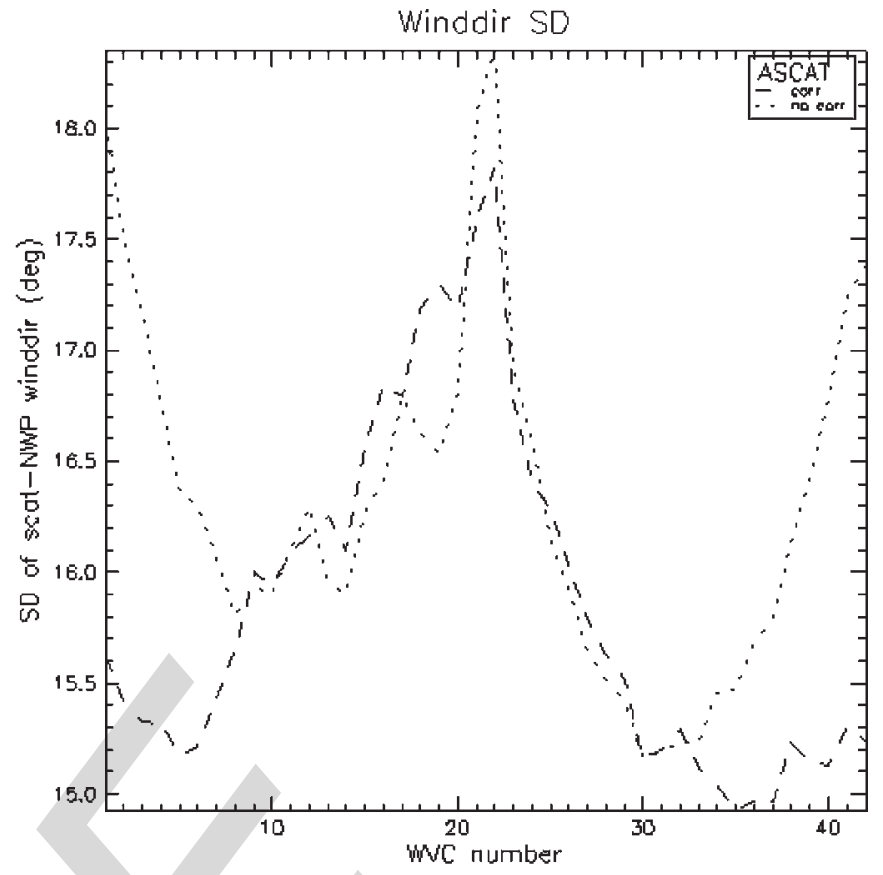

(b)

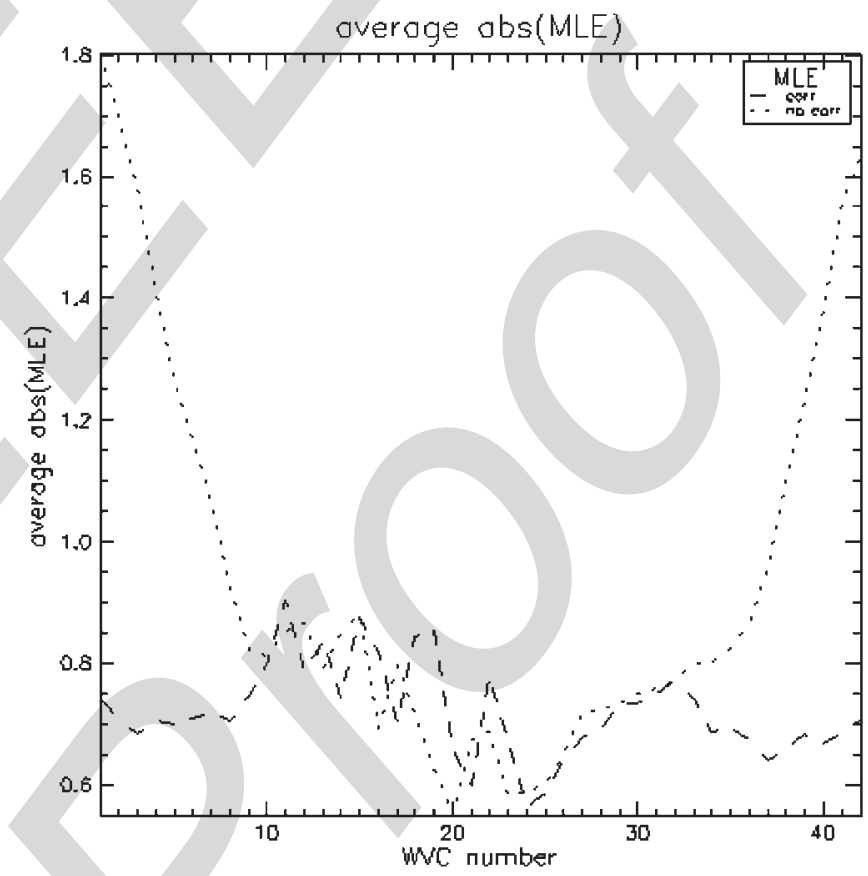

(d)

Fig. 8. (a) Wind-speed bias of ASCAT versus ECMWF winds for the period March 5, 2008 to March 11, 2008 as a function of WVC. (b) Wind-direction SD. Wind-direction statistics are for the 2-D variational ambiguity removal wind solutions for ECMWF winds larger than $4 \mathrm{~m} \cdot \mathrm{s}^{-1}$. (c) $u$ and $v$ wind component SD for the corrected and uncorrected cases. (d) Absolute MLE value averaged per WVC for the corrected and uncorrected cases.

for the corrected case compared to the uncorrected case. The maximum likelihood estimation (MLE) is a measure of how well a measurement triplet fits the GMF. Fig. 8(d) shows the MLE as a function of WVC for the corrected and uncorrected cases. Clearly, a reduction in MLE can be seen for the WVCs with high incidence angle due to the corrections applied.

Fig. (9) shows the 2-D histograms of the difference in wind speed and direction, and the wind vector zonal and meridional components $u$ and $v$. Winds from the modified ASCAT data produce unbiased winds, as expected, and give rms error values of $1.28 \mathrm{~m} \cdot \mathrm{s}^{-1}$ in wind speed and $15.9^{\circ}$ in wind direction. Hersbach [14] shows similar results. These values are better than those given when using ERS scatterometer data (see, e.g., [10] and [15]), showing that the wind vectors retrieved from the ASCAT data exceed those from ERS in quality. This is to be expected, as ASCAT was designed to give less measurement noise at a given resolution than the ERS scatterometer, and clearly indicates that the AWDP bias correction and wind retrieval are functioning correctly and are able to exploit the improved measurement data. 


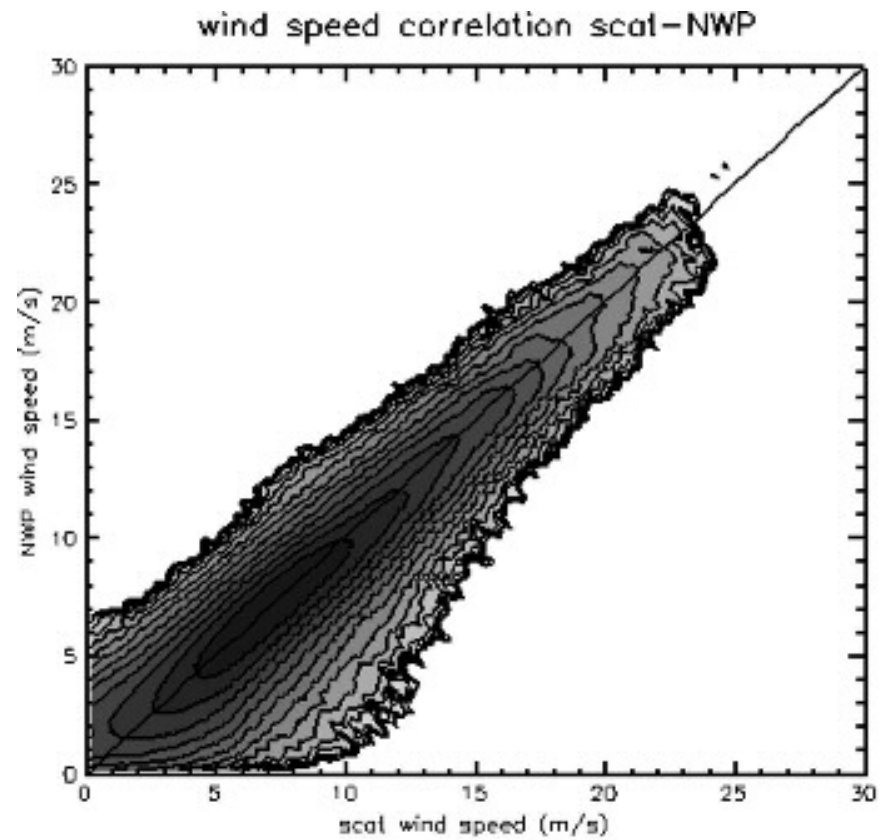

(a)

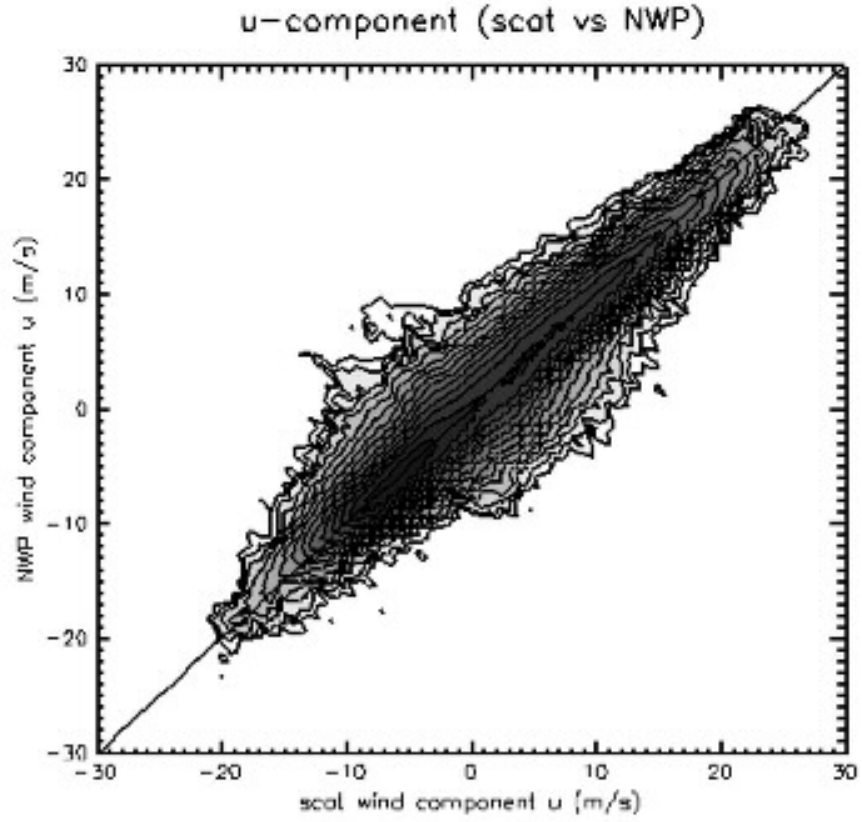

(c)

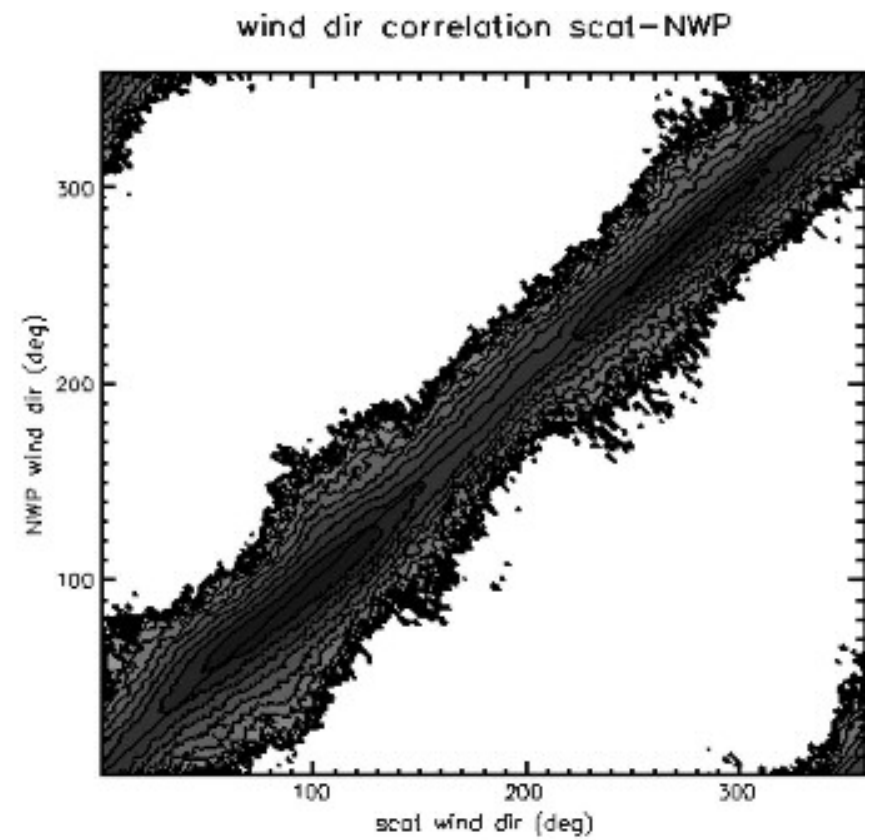

(b)

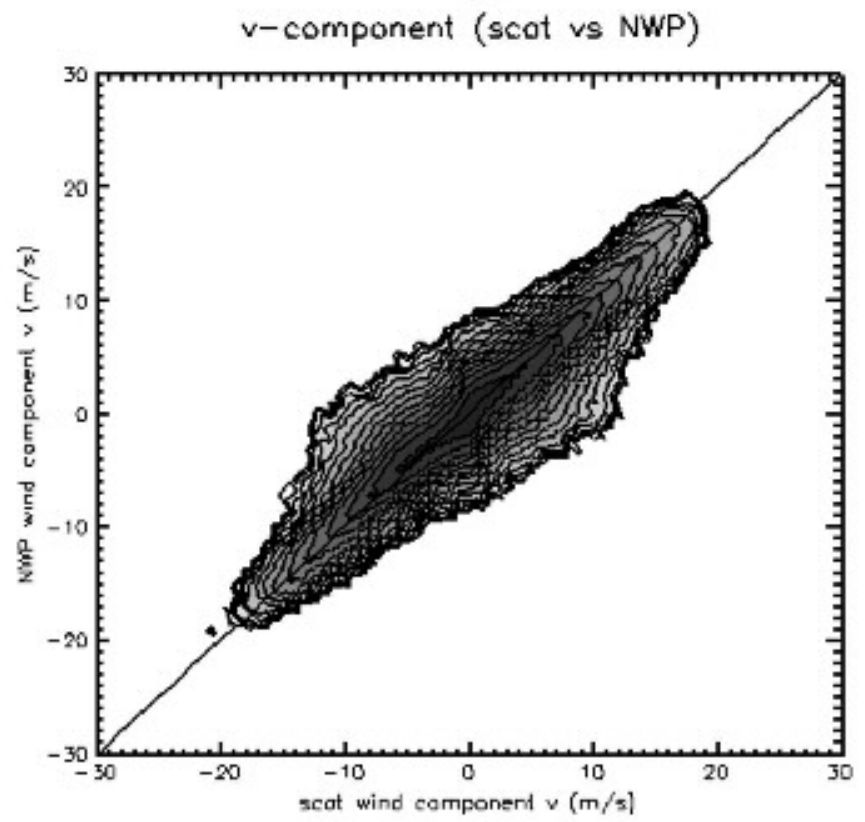

(d)

Fig. 9. Two-dimensional histograms of the retrieved wind solution versus ECMWF wind for all WVCs. Data from the period March 5, 2008 to March 11, 2008 are used. $N$ is the number of data points, $m x$ and $m y$ are the mean values along the $x$ - and $y$-axes, and cor is the Pearson correlation coefficient of the $x y$ distribution. The contour lines are in logarithmic scale, with each level being larger by a factor of two. Lowest level is 10 , and there are 15 levels in total. (a) Wind speed (bins of $0.4 \mathrm{~m} \cdot \mathrm{s}^{-1}, N=2314198, m x=7.59, m y=7.40, c o r=0.93$ ). (b) Wind direction (bins of $2.5^{\circ}$, ECMWF winds larger than $4 \mathrm{~m} \cdot \mathrm{s}^{-1}, N=1942849, m x=163.0, m y=162.9$, cor $=0.99$ ). (c) Wind component $u$ (bins of $0.4 \mathrm{~m} \cdot \mathrm{s}^{-1}, N=2314198, m x=-0.56, m y=-0.49$, cor $=0.97$ ). (d) Wind component $v$ (bins of $0.4 \mathrm{~m} \cdot \mathrm{s}^{-1}, N=2314198, m x=-0.24, m y=-0.20$, cor $=0.94$ ).

The winds produced by the AWDP can also be compared against buoy winds. An AWDP wind and a buoy wind are considered to be collocated if the distance between the WVC center and the buoy location is less than $17.7 \mathrm{~km}$ (for comparison, the ASCAT WVC spacing is $25 \mathrm{~km}$ ) and the acquisition time difference is less than $30 \mathrm{~min}$. These criteria give about $2500 \mathrm{col}-$ locations per month. The buoy winds are available hourly after averaging the wind speed and direction over a 10-min period.

Fig. 10(a) shows the wind-speed bias and SD as a function of the wind speed from one month of collocated data. Fig. 10(b) shows the bias and $\mathrm{SD}$ of the wind direction. Within the range of $3-13 \mathrm{~m} \cdot \mathrm{s}^{-1}$, the wind-speed bias is small, only a few tenths of meters per second, and outside this range, the scatterometer winds are less than the buoy winds by up to $1 \mathrm{~m} \cdot \mathrm{s}^{-1}$. Windspeed retrieval in low and high wind-speed regimes is an area of active research [16].

Taking an average over the five-month period from November 2007 to May 2008 results in a wind-speed bias of $-0.08 \mathrm{~m} \cdot \mathrm{s}^{-1}$ for AWDP versus buoy winds and an SD in the $u$ and $v$ components of 1.76 and $1.79 \mathrm{~m} \cdot \mathrm{s}^{-1}$, respectively [17]. 


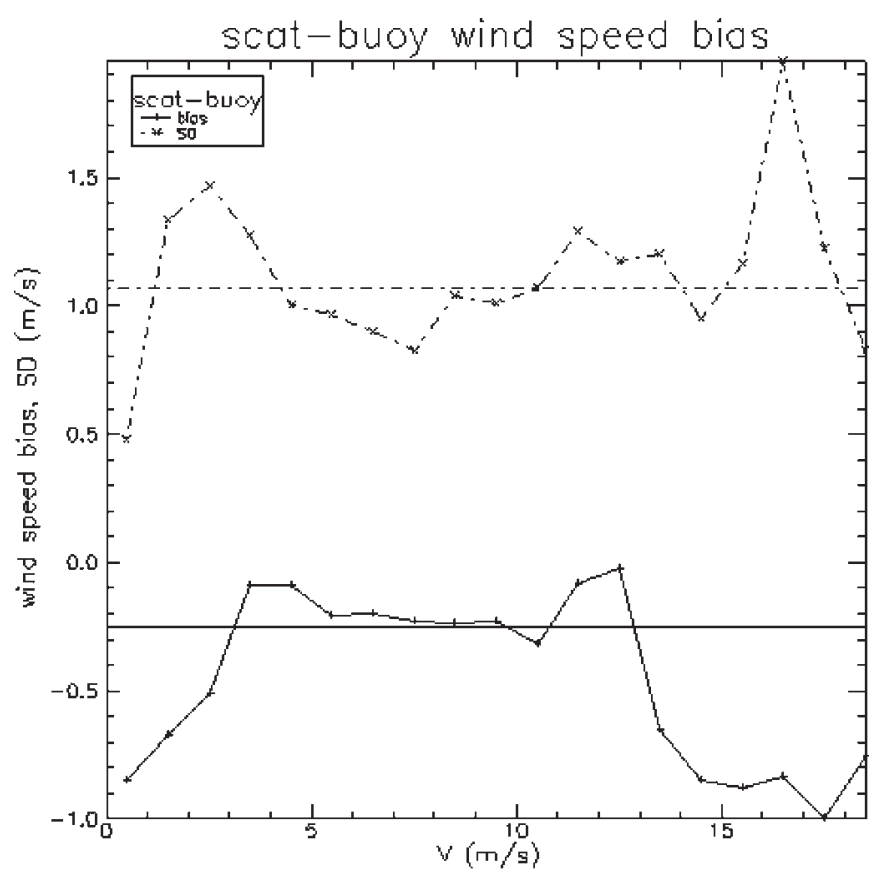

(a)

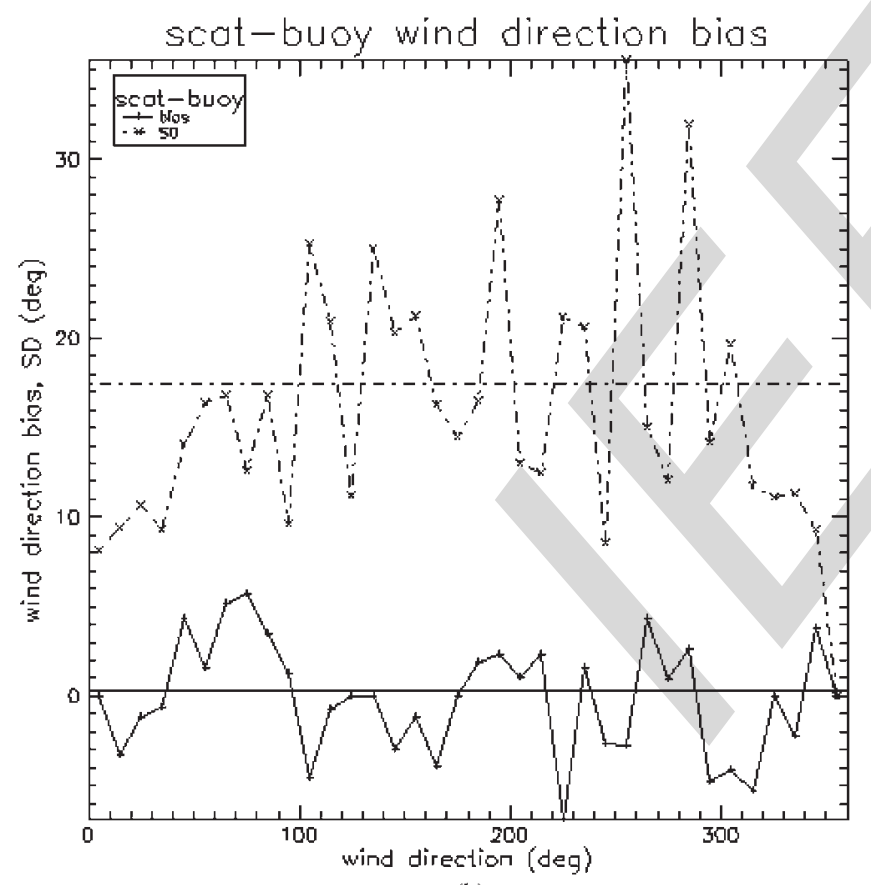

(b)

Fig. 10. Scatterometer-buoy bias and SD for wind speed and direction. Data are from May 2008. The average values of bias and SD are indicated as straight horizontal lines.

This is within the range expected [18], [19], which again confirms that the bias correction procedure and the AWDP wind retrieval are functioning correctly.

The ASCAT wind product accuracy requirements were specified as $2 \mathrm{~m} \cdot \mathrm{s}^{-1}$ with respect to a true wind reference [20]. Although the rms values given above do not provide a measure of the ASCAT wind accuracy alone, but rather the combined error of ASCAT and ECMWF or buoy winds, it is clear that the ASCAT wind product meets this requirement.

\section{Summary AND CONCLUSION}

The bias between calibrated ASCAT data and the CMOD5.n ocean backscatter GMF has been determined using a combination of visualization tools (to determine a midbeam bias and the fore/aft beam skew) and a comparison between retrieved and ECMWF winds (to determine a wind-speed bias). Below $55^{\circ}$ incidence, the bias is found to be about $0.3 \mathrm{~dB}$ in all beams, indicating that there is a difference in calibration between the ASCAT data and the ERS data used to derive the GMF. Above $55^{\circ}$, the bias rises to about $0.8 \mathrm{~dB}$, which could indicate not only a problem in the ASCAT calibration but also deficiencies in CMOD5.n which has been poorly validated in this incidence angle regime, since it has not been covered by the ERS scatterometer.

The calculated biases can be applied to the ASCAT data to bring them into alignment with the GMF and hence to the same calibration standard as the ERS data on which the GMF was based. Visual comparisons between corrected data and the GMF and also quantitative comparisons using the ocean calibration technique show that this process is effective. Subsequent level-1B backscatter calibrations resulted in smaller and more consistent biases for the three beams on each ASCAT swath.

AWDP applies the bias correction to ASCAT data before using CMOD5.n to retrieve wind vectors in order to produce the operational ASCAT level-2 wind product. Comparison of the product against ECMWF winds shows an rms error of approximately $1.3 \mathrm{~m} \cdot \mathrm{s}^{-1}$ in wind speed and $16^{\circ}$ in wind direction. Comparison against buoy winds shows an rms error of approximately $1.8 \mathrm{~m} \cdot \mathrm{s}^{-1}$ in the wind components. These results are better than those achieved using ERS scatterometer data, indicating that the AWDP bias correction and wind retrieval are working effectively to exploit the lower noise in ASCAT measurements compared to ERS. These results also demonstrate that the ASCAT level-2 wind product satisfies its accuracy requirements. Moreover, we note that the bias correction technique allows AWDP to be insensitive to the status of the ASCAT backscatter calibration, which has changed over time as additional transponders and improved calibration algorithms were used, enabling it to produce high-quality winds as soon as the first ASCAT backscatter data became available and have remained constant in quality and characteristics ever since.

The consistency of ASCAT and ERS scatterometer winds allowed the quick and beneficial application of ASCAT winds [21]. Other techniques (such as cross calibration of ERS and ASCAT, or comparison of ERS and ASCAT backscatter over other geophysical targets) will be useful to validate the backscatter calibration. However, the bias correction technique described in this paper is capable of modifying the ASCAT backscatter data set so that it is consistent with ERS data which have been proven to be useful for sea ice and soil moisture applications.

A set of incidence-angle-dependent coefficients will be tested to modify the CMOD5.n GMF and maintain or improve the quality of the ASCAT winds, fully exploiting the ASCAT instrument and the three-transponder calibration for ASCAT. 


\section{ACKNOWLEDGMENT}

The authors would like to thank their colleagues from the Royal Netherlands Meteorological Institute (KNMI), namely, A. Verhoef, J. Vogelzang, and J. de Kloe, for their interest in this work, stimulating discussions, and helpful advice in software issues. This work is mainly done in the framework of the Ocean and Sea Ice Satellite Application Facility (OSI SAF) and its visiting scientist scheme. The ASCAT winds produced at KNMI can be obtained free of charge from the OSI SAF Web site. AWDP has been funded by EUMETSAT in the context of the Numerical Weather Prediction (NWP) SAF and can be obtained free of charge from the NWP SAF Web site.

\section{REFERENCES}

[1] J. Figa-Saldaña, J. J. W. Wilson, E. Attema, R. Gelsthorpe, M. R. Drinkwater, and A. Stoffelen, "The Advanced Scatterometer (ASCAT) on the meteorological operational (MetOp) platform: A follow on for European wind scatterometers," Can. J. Remote Sens., vol. 28, no. 3, pp. 404-412, 2002.

[2] J. J. W. Wilson, C. Anderson, M. A. Baker, H. Bonekamp, J. Figa Saldaña, R. G. Dyer, J. A. Lerch, G. Kayal, R. V. Gelsthorpe, M. A. Brown, E. Schied, S. Schutz-Munz, F. Rostan, E. W. Pritchard, N. G. Wright, D. King, and Ü. Önel, "Radiometric calibration of the Advanced Wind Scatterometer radar ASCAT carried on-board the METOP-A satellite," IEEE Trans. Geosci. Remote Sens., 2009, to be published.

[3] A. Verhoef and A. Stoffelen, "Validation of ASCAT 12.5-km winds," Ocean and Sea Ice SAF Technical Note SAF/OSI/CDOP/KNMI/TEC/ RP/147, Feb. 2009. Ver. 1.2. [Online]. Available: www.knmi.nl/ scatterometer/publications/pdf/ASCAT_validation_125.pdf

[4] M. Portabella and A. Stoffelen, "On Bayesian scatterometer wind inversion," IEEE Trans. Geosci. Remote Sens., vol. 44, no. 6, pp. 1523-1533, Jun. 2006.

[5] J. Vogelzang, A. Stoffelen, A. Verhoef, J. de Vries, and H. Bonekamp, "Validation of two-dimensional variational ambiguity removal on Seawinds scatterometer data," J. Atmos. Ocean. Technol., vol. 26, pp. 1229 $1245,2009$.

[6] A. Verhoef, M. Portabella, A. Stoffelen, and H. Hersbach, CMOD5.n-The CMOD5 GMF for Neutral Winds, 2008. EUMETSAT SAF/OSI/CDOP/KNMI/TEC/TN/165.

[7] J. Verspeek, M. Portabella, A. Stoffelen, and A. Verhoef, Calibration and Validation of ASCAT Winds. de Bilt, The Netherlands: KNMI, 2008. EUMETSAT SAF/OSI/KNMI/TEC/TN/163.

[8] A. Stoffelen, "A simple method for calibration of a scatterometer over the ocean," J. Atmos. Ocean. Technol., vol. 16, no. 2, pp. 275-282, Feb. 1999.

[9] A. Stoffelen and D. Anderson, "Scatterometer data interpretation: Measurement space and inversion," J. Atmos. Ocean. Technol., vol. 14, no. 6, pp. 1298-1313, Dec. 1997.

[10] A. Stoffelen, "Scatterometry," Ph.D. dissertation, Univ. Utrecht, Utrecht, The Netherlands, 1998.

[11] H. Hersbach, A. Stoffelen, and S. de Haan, "An improved C-band scatterometer ocean geophysical model function: CMOD5," J. Geophys. Res., vol. 112, no. C3, pp. C03 006-1-C03 006-18, Mar. 2007.

[12] J. Verspeek, "Scatterometer calibration tool development," KNMI, de Bilt, The Netherlands, EUMETSAT SAF/OSI/KNMI/TEC/RP/092, 2006.

[13] M. Freilich, H. Qi, and R. S. Dunbar, "Scatterometer beam balancing using open-ocean backscatter measurements," J. Atmos. Ocean. Technol., vol. 16, no. 2, pp. 283-297, Feb. 1999.

[14] H. Hersbach, "CMOD5.N: A C-band geophysical model function for equivalent neutral wind," ECMWF, Reading, U.K., 2008. Tech. Memo. 554.

[15] H. Hersbach, "CMOD5: An improved geophysical model function for ERS C-band scatterometry," ECMWF, Reading, U.K., 2003. Tech. Memo. 395.

[16] A. Stoffelen, "Toward the true near-surface wind speed: Error modeling and calibration using triple collocation," J. Geophys. Res., vol. 103, no. C4, pp. 7755-7766, Apr. 1998.

[17] J. Verspeek, A. Stoffelen, M. Portabella, A. Verhoef, and J. Vogelzang, "ASCAT scatterometer ocean calibration," in Proc. IGARSS, 2008, pp. 2539-2542.

[18] M. Portabella and A. Stoffelen, "On scatterometer ocean stress," J. Atmos. Ocean. Technol., vol. 26, no. 2, pp. 368-382, Feb. 2009.
[19] A. Bentamy, D. Croize-Fillon, and C. Perigaud, "Characterization of ASCAT measurements based on buoy and QuikSCAT wind vector observations," Ocean Sci. Discuss., vol. 4, pp. 265-274, 2008.

[20] D. Klaes, EPS Programme, End User Requirements Document, 2000. EUMETSAT, EUM.EPS.MIS.REQ.93.001, Issue 4 Rev 3.

[21] M. Takahashi and Y. Tahara, "Status and Plans of Using the Scatterometer Winds in JMA's Data Assimilation and Forecast System," NASA Ocean Vector Wind Science Team Meeting, Seattle, WA, Nov. 19-21, 2008. [Online]. Available: coaps.fsu.edu/scatterometry/ meeting/docs/2008/othersci/takahashi.pdf

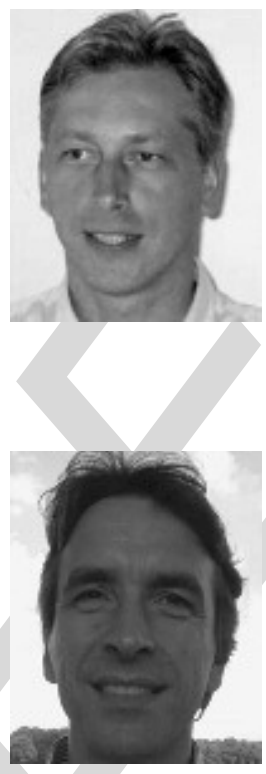

Jeroen Verspeek was born in The Netherlands on July 2, 1962. He received the M.Sc. degree in physics from the Technical University of Eindhoven, Eindhoven, The Netherlands, in 1988.

$\mathrm{He}$ is currently with the Royal Netherlands Meteorological Institute (KNMI), De Bilt, The Netherlands, working on scatterometer data interpretation, inversion, calibration, validation, and quality monitoring.

\section{ADM-Aeolus Doppler Wind Lidar mission.}

Ad Stoffelen was born in The Netherlands on February 25, 1962. He received the M.Sc. degree in physics from the Technical University of Eindhoven, Eindhoven, The Netherlands, in 1987 and the Ph.D. degree in meteorology on scatterometry from the University of Utrecht, Utrecht, The Netherlands.

$\mathrm{He}$ is currently with the Royal Netherlands Meteorological Institute (KNMI), De Bilt, The Netherlands, where he is responsible for the Advanced Scatterometer wind products. He is also deeply involved in the European Space Agency ADM-Ae

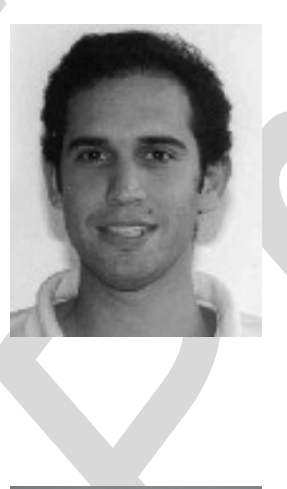

Marcos Portabella was born in Spain on October 14, 1970. He received the B.Sc. and Ph.D. degrees in physics from the University of Barcelona, Barcelona, Spain, in 1994 and 2002, respectively, and the M.Sc. degree in remote sensing from the Institute for Space Studies of Catalonia, Barcelona, Spain, in 1995.

$\mathrm{He}$ is currently with the Unidad de Tecnología Marina (UTM-CSIC), Barcelona, working on satellite remote sensing. In particular, he is involved in scatterometry and L-band radiometry.

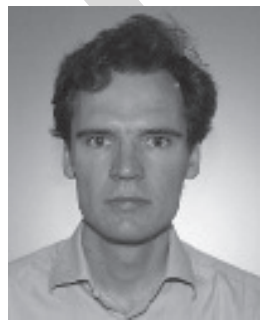

Hans Bonekamp was born in The Netherlands, on February 12, 1967. He received the M.Sc. degree in applied mathematics from the University of Twente, Enschede, The Netherlands, the M.Sc. degree in industrial mathematics from the University of Eindhoven, Eindhoven, The Netherlands, and the $\mathrm{Ph} . \mathrm{D}$. degree from Utrecht University, Utrecht, The Netherlands, in 2001. His Ph.D. thesis was on the air-sea fluxes for climate modeling.

$\mathrm{He}$ is currently an Ocean Mission Scientist with the European Organisation for the Exploitation of Meteorological Satellites (EUMETSAT), Darmstadt, Germany.

Craig Anderson, photograph and biography not available at the time of publication. 


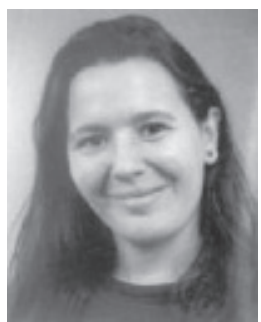

Julia Figa Saldaña was born in Spain. She received the M.S. degree in civil engineering from the Universitat Politecnica de Catalunya, Barcelona, Spain, in 1993.

Since 1993, she has been involved in radar remotesensing processing and applications. She is currently an ASCAT Product Expert with the Meteorological Operations Division, European Organisation for the Exploitation of Meteorological Satellites (EUMETSAT), Darmstadt, Germany. 